\title{
And then they took away the pigeon holes
}

Previously published at www.cmaj.ca

$\mathrm{W}$

e used to have large turnouts for the meetings of the medical staff of the Calgary General Hospital, the one they shut down and imploded in 1998 because we didn't need it any longer. That was in the days when the administrator's role was to help us, the medical staff, to do the job: to provide the best possible care for our patients. We worked on hospital committees on a volunteer basis as part of a local community with grassroots responsibility and we were closely connected to one another and the institution. Then they took away the pigeon holes.

During the 1980s serious change was afoot in health care. We began to address the need for a system in health care, something that had not really existed before. This needed to happen. We needed to eliminate inefficiencies and duplication of services. We needed to manage, to plan, to communicate, to integrate all of the providers, institutions and programs into something efficient and cost-effective. We had to bring all of the resources available to bear on the work to be done and to provide for the highest quality of care. And so government began to implement a high-level approach to the management of health.

An early innovation afforded us at the Calgary General Hospital was an electronic patient management program. One of its functions was to notify a physician that a consultation was required or that his or her patient had been admitted to hospital. Before that we had relied on paper messages left in a set of pigeon holes. Unfortunately, the electronic system performed erratically - it was regularly "down." When we heard that the paper system of doctor-to-doctor communication was to be eliminated, the medical staff unanimously passed a motion that the pigeon hole system be kept as a backup, for reasons of patient safety. The next day it was gone. A clear and

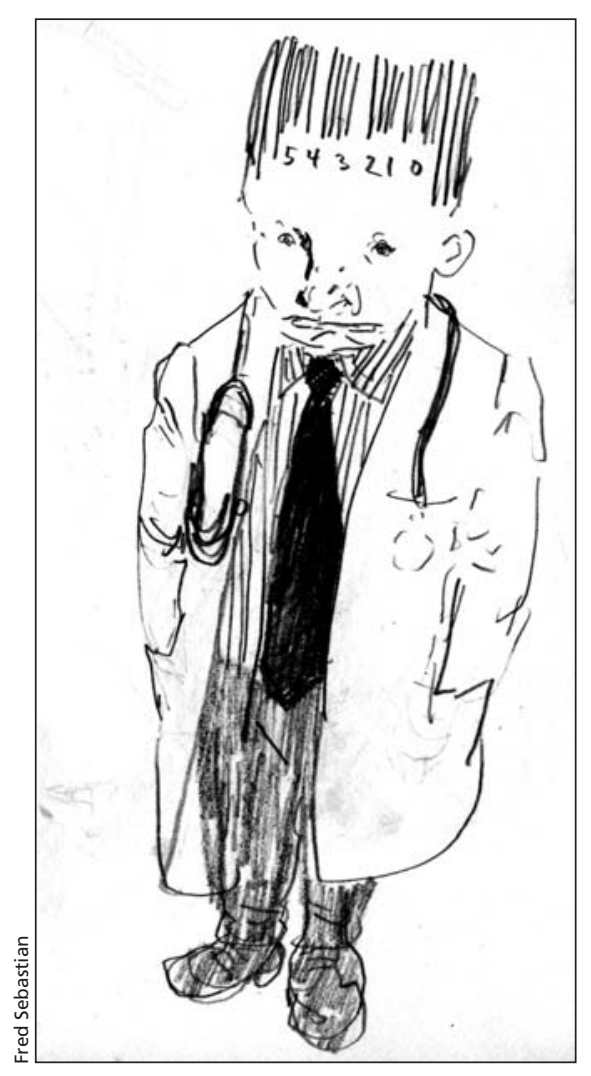

emphatic declaration was made that power had shifted from the medical staff to the hospital administration.

Over the next few years we faced an era of reduced spending in health care. Some doctors were leaving for the United States; many thought that this was for better pay. A couple of physicians recounting their difficult choice in the Calgary General Hospital doctor's lounge said they were leaving to work in an environment in which they had control of their workplace so they could provide for the needs of their patients; they were not leaving for better pay.

Lessons from the world of business have been effectively applied to health care. Organizational principles and an understanding of the importance of standardization to the quality of care are good examples. Much of the work of the health system is, of course, business - the hiring and training of staff, planning and building of hospitals, finance, information management, purchasing of equipment and supplies, contracting with service providers, etc. - and requires business expertise. And there has been a dramatic shift of power to individuals with business backgrounds.

But health care is much more than "bricks and mortar." It is immensely complicated and personal. The provision of care and the prevention of disease and disability require skills that are highly individualized and complex. Managers require knowledge and experience beyond those of business.

The role and status of physicians has changed irrevocably. Our involvement is less personal. We are now paid for the administrative functions we used to provide voluntarily. We are better paid than we were in the '90s, but our sense of ownership and control has diminished. We don't have the sense of community we used to have. We are more like "provider units" in the health care machine and we are not as well connected to each other.

We now have a health system run via proxy by government with experts from the corporate community at the helm. The strategies and values of business are paramount. We are a considerable distance from the very local, communitybased world of the recent past. It will take some effort to find new ways for physicians and physician organizations to re-establish an active and meaningful role in managing health that helps to ensure the system remains rooted in both the science and art of medicine.

\section{Guido Van Rosendaal MD}

Departments of Community Health

Sciences and Internal Medicine

University of Calgary

Calgary, Alta.

Have you got an opinion about this article? Post your views at www.cmaj.ca. Potential Salon contributors are welcome to send a query to salon@ cmaj.ca.

All editorial matter in CMAJ represents the opinions of the authors and not necessarily those of the Canadian Medical Association. 